\title{
Efecto de la fertilización potásica en helecho cuero (Rumohra adiantiformis (G. Forst.) Ching) y su influencia sobre la incidencia de Colletotrichum sp.
}

\section{Effect of potassium fertilization on the leatherleaf fern (Rumohra adiantiformis (G. Forst.) Ching) and Colletotrichum sp. incidence}

PABLO FERNANDO SOLER ${ }^{1}$

ARLETTE IVONNE GIL C. ${ }^{1,2}$

Plantas de helecho cuero en Anolaima (Cundinamarca).

Foto: P.F. Soler

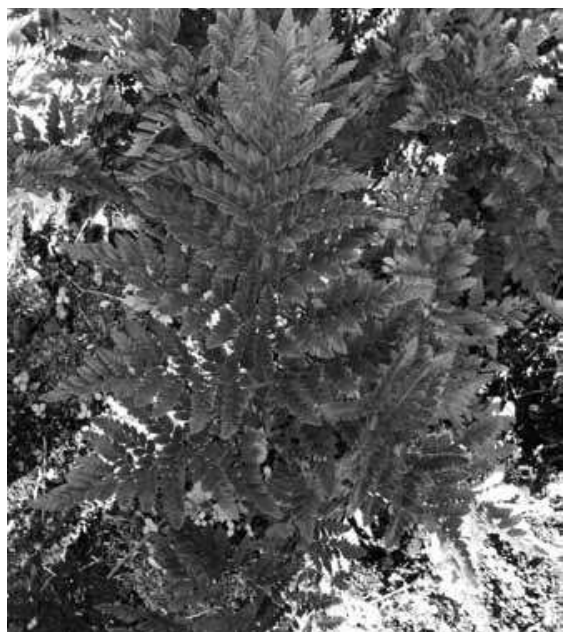

\section{RESUMEN}

Este estudio se llevó a cabo con el fin de analizar el efecto de la fertilización potásica en forma edáfica y foliar, en distintas dosis (200, 300 y $400 \mathrm{~kg} \mathrm{ha}^{-1}$ de potasio para aplicaciones edáficas, y 1; 1,5 y $2 \mathrm{~L} \mathrm{ha}^{-1}$ de potasio para aplicaciones foliares) y en diferentes estados de la fronda de helecho cuero (turión de emergencia y fronda cele) y su influencia en el control de Colletotrichum sp. Las variables evaluadas fueron incidencia de Colletotrichum sp. y producción de frondas de helecho por $\mathrm{m}^{2}$. Se encontró que fertilizaciones edáficas con $\mathrm{KCl}$ en dosis de $300 \mathrm{~kg} \mathrm{ha}^{-1}$ cuando la fronda de helecho presentó el estado de turión de emergencia, complementadas con aspersiones foliares de potasio a razón de 1,5 $\mathrm{L} \mathrm{ha}^{-1}$ en el momento en que la fronda alcanzó el estado fenológico cele, mostró una menor incidencia de Colletotrichum sp., asimismo como una mayor producción de frondas por $\mathrm{m}^{2}$. Fertilizaciones edáficas o foliares para un solo estado de la fronda no mostraron un adecuado control de la enfermedad.

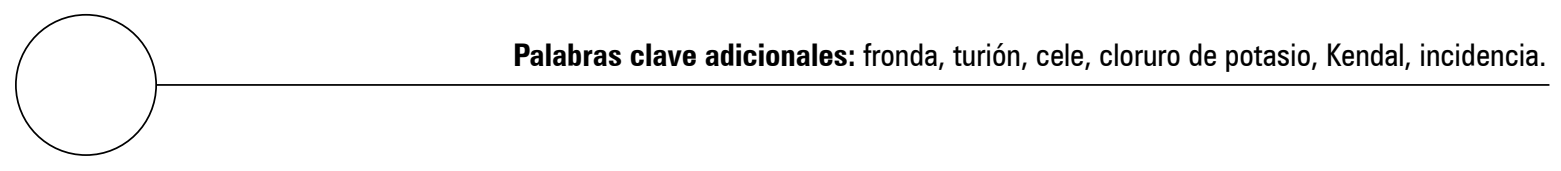

Facultad de Ciencias Agropecuarias, Universidad de Cundinamarca, Fusagasugá (Colombia).

2 Autor para correspondencia. arlettegil@hotmail.com 


\section{ABSTRACT}

This study was carried out with the purpose of analyzing the effect of soil and foliar fertilization with potassium, at different doses $\left(200,300\right.$ y $400 \mathrm{~kg} \mathrm{ha}^{-1}$ of potassium for soil fertilizations and 1, 1.5 and $2 \mathrm{~L}$ $\mathrm{ha}^{-1}$ of potassium for foliar applications) on the frond stages in the leatherleaf fern (shoot emergence and unfurling croziers cele) and its influence over the control of Colletotrichum sp. The variables evaluated were incidence of Colletotrichum sp. and production of fronds per $\mathrm{m}^{2}$. It was found that soil fertilization with $\mathrm{KCl}$ at a dose of $300 \mathrm{~kg} \mathrm{ha}^{-1}$ when the fern fronds showed shoot emergence, supplemented with a foliar spray of potassium at $1.5 \mathrm{~L} \mathrm{ha}^{-1}$ when the leaves reached the unfurling phenological stage cele, showed a lower incidence of Colletotrichum sp. and a greater production of fronds per $\mathrm{m}^{2}$. Soil or foliar fertilization for a single frond stage did not show an adequate control of the disease.

Additional key words: frond, shoot, unfurling croziers cele, potassium chloride, Kendal, incidence.

Fecha de recepción: 08-03-2011

Aprobado para publicación: 27-05-2011

INTRODUCCIÓN

Colombia posee 7.509 ha dedicadas a la producción de flores y follajes lo que equivale a exportaciones por $22.300 \mathrm{t}$, destacándose los departamentos de Cundinamarca con $76 \%$ y Antioquia con $19 \%$ como principales productores. En Cundinamarca se destacan la producción de follajes en los municipios de Anolaima y Cachipay, dadas las condiciones agroecológicas y la alta vocación que tiene la zona por este tipo de explotaciones, además de su ubicación frente a los canales de comercialización, principalmente bouqueteras. Según las Umata, se registran 251 ha destinadas a la producción de follajes de las cuales 160 están sembradas en helecho cuero (Rumohra adiantiformis (G. Forst.) Ching) (Asocolflores, 2009).

Muchas de las flores que se exportan suelen ser enviadas en una presentación de valor agregado o bouquet, el cual consta de varios productos, entre ellos algún tipo de verde que resalte el valor estético y la belleza de las flores con las que éste es armado, siendo el helecho cuero uno de los follajes más deseados, dada su vida útil en florero y la forma de su fronda, con lo cual los floricul- tores buscan disminuir la exportación de flor sólida y generar mayores ganancias en el producto primario. El helecho hoja de cuero es utilizado comercialmente en arreglos florales (Baldauf et al., 2007). Asocolflores reportó que durante 2009 se exportaron $69.770 \mathrm{t}$ de productos diferentes a los tradicionales y dentro de las cuales se hace referencia a bouquets.

Para el primer semestre de 2009, el cual coincide con las dos fiestas de mayor demanda (San Valentín y día de las madres) se reportaron importaciones por $530.000 \mathrm{~kg}$ de flores y follajes, con respecto a los $412.000 \mathrm{~kg}$ que se registraron durante 2008, lo cual representa una variación con respecto al año 2008 del 28,8\% (Ministerio de Comercio Exterior, 2009).

El helecho cuero se caracteriza por tener hojas brillantes, de intenso color verde y consistencia recia, cuyo pecíolo crece recto y fuerte, tiene buena vida poscorte y es el follaje el que se usa en los arreglos florales (Robertson et al., 1983). Las hojas, que reciben el nombre de frondas, presentan divisiones primarias conocidas como pinnas y 
secundarias llamadas pínulas. Sobre el envés de las hojas se forman estructuras llamadas soros, compuestas por grupos de esporas resguardadas dentro de los esporangios y que conforman el principal mecanismo reproductivo de esta especie en la naturaleza. Los tallos son en realidad rizomas escamosos a partir de los cuales se forman las hojas; las escamas inicialmente blancas se tornan pardas más adelante. Los pecíolos se conocen comúnmente con el nombre de estípites. La planta es compacta y frondosa y alcanza una altura promedio entre 30 y $90 \mathrm{~cm}$ según las condiciones del cultivo (Atehortua et al., 1997).

La reproducción comercial del helecho cuero se realiza vegetativamente a partir de un rizoma. En el género Rumohra se da una buena capacidad de supervivencia debido a la gran cantidad de yemas en latencia que hay en los rizomas, las cuales generan nuevas frondas una vez que se ha cosechado la fronda que la subtiende (al parecer se presenta una dominancia de las hojas viejas, cuyo efecto inhibitorio se debe a las auxinas) (Fitts, 1983).

Milton (1988) clasificó siete estadios o etapas de desarrollo en esta especie:

Bastón contraído o turión de emergencia: se observa la cabeza de la fronda que empieza a emerger del suelo.

Bastón extendido: el turión se ha extendido hasta casi tomar la forma de la fronda abierta, las puntas de las pínulas aún se observan enrolladas.

Fronda cele o inmadura: recién abierta en su totalidad, de un color verde muy claro y brillante.

Fronda madura: fronda en punto de cosecha, de un color verde oscuro y con una textura coriácea.

Fronda sobremadura: la fronda después de varias semanas de haber alcanzado la madurez o el punto de corte comienza a tornarse púrpura.
Fronda muerta: la fronda adquiere una coloración amarilla o rojiza en su totalidad.

Pecíolo de fronda cortada: parte del raquis que queda usualmente dentro del suelo una vez la fronda ha sido cortada.

Se ha observado que la planta tarda de cuatro a siete semanas para pasar del estado de bastón al de fronda inmadura y de cinco a diez semanas para pasar de fronda inmadura a fronda madura, dando paso a la cosecha luego de su maduración, hasta cinco semanas después (Stamps, 1989). Durante el inicio del desarrollo de la fronda, el crecimiento depende de las reservas provenientes del rizoma (primero se consume las del rizoma que produce la hoja y luego, si es necesario, la de los rizomas de almacenamiento), hasta que se ha abierto la segunda pinna de la fronda, momento en el cual la hoja cambia de estatus de vertedero (órgano predominante heterotrófico, en crecimiento activo, en donde se mueven materiales desde otros lugares de la planta) a fuente (crecimiento de metabolitos que declinan luego de madurar) (Monge, 1992). La tasa de crecimiento es inicialmente lenta, dándose en primer lugar el alargamiento del estipe, hasta que se acelera la acumulación de biomasa cuando se abre la primera pinna, el mismo decrece cuando llega a la madurez. El peso seco se redistribuye en $60 \%$ de pinas y $40 \%$ de estipe y raquis (González et al., 1998).

Entre las principales limitantes que afectan los niveles de producción, se destacan algunas enfermedades fúngicas, principalmente Colletotrichum sp., la cual es causante de pérdidas considerables de frondas potencialmente exportables, dada la agresividad del patógeno y la susceptibilidad de la especie. El ataque se caracteriza por necrosar los tejidos de las pínulas de las frondas en estado inmaduro o cele, e incluso pudiendo llegar a darse la situación en la cual la fronda presenta una apariencia quemada, dada la severidad del ataque del patógeno, lo que le da el nombre popular de antracnosis o "chamusquina". 
En helecho cuero los síntomas de antracnosis consisten en la necrosis de las partes exteriores de las frondas. Las lesiones pueden aparecer en o cerca de la base de los pecíolos. El patógeno aparentemente es incapaz de infectar el rizoma bajo condiciones naturales. Un ataque severo de antracnosis puede llegar a afectar más del 50\% de las hojas en un periodo relativamente corto (Berrocal, 1996).

Debido a esta situación muchos productores desean basar la estrategia de protección de sus cultivos del ataque de Colletotrichum sp. de manera diferente al control químico y podas de sanidad vegetal, dados los altos costos en mano de obra e insumos que representan este tipo de prácticas. El manejo nutricional a través de la fertilización es un control cultural importante en las enfermedades de las plantas y un componente integral de la producción agrícola (Huber, 1989). Las plantas que reciben una nutrición mineral balanceada son más tolerantes a las enfermedades, es decir, tienen mayor capacidad para protegerse de nuevas infecciones y de limitar las ya existentes, que cuando uno o más nutrientes son abastecidos en cantidades excesivas o deficientes (Fageria, 1997).

Los nutrientes pueden, además, incrementar o disminuir la resistencia o tolerancia de los cultivos a los patógenos. Estas pueden ser incrementadas por cambios en la anatomía (células epidermales gruesas con alto grado de lignificación o silificación) y en las propiedades fisiológicas y bioquímicas (alta producción de inhibidores o sustancias repelentes). El potasio está dedicado a la elongación de los tallos y raquis, por lo cual es utilizado para la protección contra enfermedades ya que tiene un efecto en el engrosamiento de las paredes celulares (Jones, 1987).

Un buen suplemento de potasio puede incrementar la resistencia de las plantas debido a su función en la osmorregulación, en el estatus energético y en la síntesis de compuestos de alto peso molecular (Marschner, 2002). El potasio pro- bablemente ejerce los mayores efectos sobre las enfermedades a través de funciones metabólicas específicas que alteran las relaciones de compatibilidad del ambiente hospedero-parásito (Kafkafi et al., 2001). Las intrincadas relaciones entre la nutrición potásica y las funciones metabólicas y el crecimiento, así como sus interrelaciones con algunos otros nutrientes dentro de la planta y el suelo proveen una amplia oportunidad para que el potasio modifique la resistencia o susceptibilidad a enfermedades (Pervez et al., 2007).

Buscando disminuir las pérdidas ocasionadas por Colletotrichum sp. en el cultivo de helecho cuero, se creó la necesidad de llevar a cabo el presente ensayo, utilizando el potasio en diferentes dosis, métodos de aplicación y estados de madurez de las frondas, para determinar la forma más eficiente en el manejo del patógeno disminuyendo su incidencia sobre la producción y generando una mayor emergencia de turiones o nuevas frondas.

\section{MATERIALES Y MÉTODOS}

Esta investigación se llevó a cabo en el municipio de Anolaima (Cundinamarca), Vereda Tocarema Alta, finca "Villa Laura", ubicada a los $4^{\circ} 45^{\prime} 40^{\prime}$ $\mathrm{N}$ y 740 27' 54"O a una altitud de 1.657 msnm, temperatura promedio $19^{\circ} \mathrm{C}$, humedad relativa de $85 \%$ y una precipitación promedio anual de $1.500 \mathrm{~mm}$.

Se empleó un diseño experimental de bloques completos al azar (BCA) con seis tratamientos $y$ cuatro repeticiones por tratamiento para un total de 24 unidades experimentales (tabla 1). Se realizaron cuatro repeticiones en el tiempo con el fin de disminuir el error experimental.

El estudio fue realizado en una plantación comercial. Se marcó un cuadro dentro del lote con un área de $1.026 \mathrm{~m}^{2}$ distribuidos de la siguiente manera: parcelas de $60 \mathrm{~m}^{2}$ con un distanciamiento entre sí de $2 \mathrm{~m}$. Una vez trazada el área 
Tabla 1. Tratamientos utilizados en el estudio del efecto de la fertilización potásica en helecho cuero $(R$. adiantiformis (G. Forst.) Ching) sobre la incidencia de Colletotrichum sp.

\begin{tabular}{|c|c|c|}
\hline Tratamiento & Método de aplicación & Estado fenológico \\
\hline $\mathrm{T} 1$ & Aplicación edáfica de potasio (KCl: $400 \mathrm{~kg} \mathrm{ha}^{-1}$ ) & Turión de emergencia ${ }^{1}$ \\
\hline $\mathrm{T} 2$ & Aplicación edáfica de potasio (KCl: $400 \mathrm{~kg} \mathrm{ha}^{-1}$ ) & Fronda cele ${ }^{2}$ \\
\hline T3 & Aplicación foliar de potasio (Kendal: $2 \mathrm{~L} \mathrm{ha}^{-1}$ ) & Turión de emergencia \\
\hline $\mathrm{T} 4$ & Aplicación foliar de potasio (Kendal: $2 \mathrm{~L} \mathrm{ha}^{-1}$ ) & Fronda cele \\
\hline $\mathrm{T} 5$ & $\begin{array}{l}\text { Aplicación edáfica de potasio (KCl: } 300 \text { kg ha-1 ) y aplicación } \\
\text { foliar de potasio (Kendal: } 1,5 \mathrm{~L} \cdot \mathrm{ha}^{-1} \text { ) }\end{array}$ & $\begin{array}{l}\text { Turión de emergencia para fertilización edáfica y } \\
\text { fronda cele para fertilización foliar }\end{array}$ \\
\hline T6 & 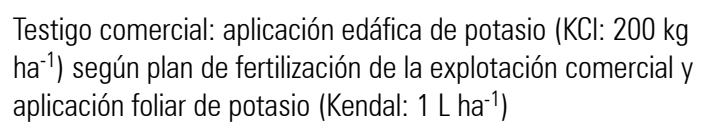 & $\begin{array}{l}\text { Turión de emergencia para fertilización edáfica y } \\
\text { fronda cele para fertilización foliar }\end{array}$ \\
\hline
\end{tabular}

${ }^{1}$ Turión de emergencia o bastón contraído: se observa la cabeza de la fronda que empieza a emerger del suelo.

2 Fronda cele 0 inmadura: recién abierta en su totalidad, de un color verde muy claro y brillante.

experimental, debido a las condiciones de las camas, se realizó una poda de sanidad con el fin de retirar de las unidades experimentales todas las frondas enfermas que pudieran alterar los resultados finales.

Las formas de aplicación del fertilizante potásico variaron de acuerdo a su presentación. Para la vía edáfica, el potasio (KCl) fue suministrado al voleo, cuando la planta presentó el estado fenológico de turión de emergencia o fronda cele. Para los tratamientos vía foliar, el potasio (producto comercial: Kendal) se suministró con bomba de espalda de 20 L de capacidad, previa calibración, en los estados fenológicos de turión de emergencia o fronda cele. Para todos los tratamientos, la aplicación del fertilizante se realizó una sola vez (tabla 1).

En cada una de las parcelas de los respectivos tratamientos, se llevó a cabo la medición de las siguientes variables:

Incidencia de Colletotrichum sp.: se evaluó marcando al azar dos puntos fijos en cada una de las parcelas, teniendo en cuenta que se muestreaba el mismo número de plantas con presencia de la enfermedad en un área determinada. Cuando la fronda alcanzó el estado de madurez de cosecha se procedió a hacer el conteo de las frondas afec- tadas por Colletotrichum sp. que se encontraban dentro de $1 \mathrm{~m}^{2}$ de área.

Producción de frondas maduras por metro cuadrado: cuando las frondas alcanzaron el estado de madurez necesario para ser cortadas, se procedió a cosechar y contar en sala de poscosecha las frondas de cada una de las parcelas.

Los datos obtenidos fueron sometidos a un análisis de varianza (Anava) y se les realizó la prueba de comparación múltiple de Tukey con una confiabilidad de 95\%. Para el análisis de los datos se utilizó el paquete estadístico SAS versión 8 e.

\section{RESULTADOS Y DISCUSIÓN}

\section{Incidencia de Colletotrichum sp.}

Se presentaron diferencias estadísticamente significativas (tabla 2), siendo la aspersión foliar de potasio de $2 \mathrm{~L} \mathrm{ha}^{-1}$ cuando la fronda alcanzó el estado cele la que presentó una mayor incidencia de Colletotrichum sp. por $\mathrm{m}^{2}$. Según Beringer y Nothdurft (1985), las plantas deficientes en potasio presentaron tejidos menos compactos como consecuencia del menor espesor de la cutícula y de la pared celular, menor formación de tejido esclerenquimatoso, menor lignificación y suberización. Esto constitu- 
Tabla 2. Efecto de la fertilización potásica sobre la incidencia de Colletotrichum sp. y producción de frondas en helecho cuero ( $R$. adiantiformis (G. Forst.) Ching).

\begin{tabular}{|c|c|c|}
\hline Tratamiento & $\begin{array}{l}\text { Incidencia de Colletotrichum sp. } \\
\text { (frondas afectadas } / \mathrm{m}^{2} \text { ) }\end{array}$ & $\begin{array}{l}\text { Producción de frondas } \\
\text { (No. frondas } / \mathrm{m}^{2} \text { ) }\end{array}$ \\
\hline $\begin{array}{l}\text { Aplicación edáfica de } \mathrm{KCl} \text { : } \\
400 \mathrm{~kg} \mathrm{ha}^{-1} \text { (turrión de emergencia) }\end{array}$ & $4,2225 c$ & $3,5850 a b$ \\
\hline $\begin{array}{l}\text { Aplicación edáfica de KCl: } \\
400 \mathrm{~kg} \mathrm{ha}^{-1} \text { (fronda cele) }\end{array}$ & $5,9700 a b$ & $3,2925 a b$ \\
\hline $\begin{array}{l}\text { Aplicación foliar de Kendal: } \\
2 \text { L ha }^{-1} \text { (turrión de emergencia) }\end{array}$ & $4,6275 \mathrm{bc}$ & $2,9650 b$ \\
\hline Aplicación foliar de potasio (Kendal: 2 L ha-1) (fronda cele) & $6,5350 \mathrm{a}$ & $3,3350 a b$ \\
\hline $\begin{array}{l}\text { Aplicación edáfica de } \mathrm{KCl}: 300 \mathrm{~kg} \mathrm{ha}^{-1} \text { (turión de emergencia) } \\
\text { y foliar de Kendal: } 1,5 \mathrm{~L} \mathrm{ha}^{-1} \text { (fronda cele) }\end{array}$ & $3,2200 \mathrm{c}$ & 4,1575 a \\
\hline Testigo comercial & $4,0050 \mathrm{c}$ & $3,5525 a b$ \\
\hline
\end{tabular}

Promedios con letras distintas indican diferencia significativa según la prueba de Tukey $(P \leq 0,05)$.

ye una barrera vulnerable para el patógeno especialmente cuando la fronda se encuentra en estado cele, que en las condiciones en las que se desarrolló este estudio osciló entre 8 y 15 d. Además, Colletotrichum sp. es favorecido por las altas temperaturas y el tiempo húmedo, sus conidios son liberados y se diseminan solamente cuando los acérvulos se encuentran húmedos y son generalmente diseminados por la lluvia (Agrios, 2007). En tal sentido, el sistema de riego empleado en el cultivo proporcionó las condiciones favorables para que se desarrollara el patógeno.

El potasio es el catión más abundante en las plantas superiores. Es esencial para la activación enzimática, la síntesis de proteínas y la fotosíntesis, además de ser mediador en la osmorregulación durante la expansión celular, los movimientos estomáticos y tropismos. También es necesario para el transporte floemático y para mantener el balance catión:anión tanto en el citosol como en la vacuola (Mäser et al., 2002). Se ha demostrado que el transporte de aminoácidos se ve incrementado con altas concentraciones de potasio, pues es crucial en la mayoría de los pasos de síntesis de proteínas, iniciando con la activación enzimática y continuando a través de la síntesis ribosomal y la degradación del mRNA (Pettigrew, 2008).
También se observó que aplicaciones en forma edáfica de $400 \mathrm{~kg} \mathrm{ha}^{-1}$ de potasio (KCl) para frondas en estado de turión de emergencia, aplicaciones edáficas de $200 \mathrm{~kg} \mathrm{ha}^{-1}$ de potasio (KCl) para frondas en estado de turión de emergencia complementadas con aspersiones de $1 \mathrm{~L} \mathrm{ha}^{-1}$ de potasio foliar (Kendal) cuando la fronda alcanzó el estado cele (testigo comercial) y fertilizaciones edáficas de potasio (KCl) en dosis de $300 \mathrm{~kg} \mathrm{ha}^{-1}$ cuando la fronda se encontró en estado de turión de emergencia complementadas con aspersiones de 1,5 $\mathrm{L} \mathrm{ha}^{-1}$ de potasio foliar (Kendal) cuando la fronda alcanzó el estado cele, no mostraron diferencias estadísticamente significativas entre sus medias pero sí con respecto a los demás.

Estos tratamientos mostraron una menor incidencia de Colletotrichum sp., lo que concuerda con lo afirmado por Marschner (2002), que cultivos fertilizados con potasio presentan una menor incidencia de enfermedades debido a una mayor síntesis de sustancias de alto peso molecular (celulosa, lignina) confirmando que la resistencia puede particularmente incrementarse cuando la planta responde al ataque de parásitos a través de la formación de barreras mecánicas (lignificación) y la síntesis de fitoalexinas. Según Angelova et al. (2010), las fitoalexinas son metabolitos secundarios de bajo peso molecular, antimicro- 
biales, que actúan como un efectivo mecanismo de defensa de las plantas contra agentes patógenos. Los antecedentes moleculares de esta inducción han sido poco investigados en plantas y tejidos intactos y está íntimamente relacionada con la morfología de la planta y su desarrollo.

De acuerdo con los resultados, las plantas que fueron fertilizadas edáficamente con potasio (KCl) para frondas en estado de turión de emergencia y posteriormente complementadas con aspersiones foliares de potasio (Kendal) cuando la fronda alcanzó el estado cele, mostraron una menor incidencia de la enfermedad, lo que confirma lo encontrado por Reuveni y Reuveni (1998) en plantas de pepino (Cucumis sativus L.), que con aplicaciones foliares de fosfato monopotásico en solución al 1\% se indujo el sistema de resistencia a enfermedades como mildeo polvoso.De esta manera se concluyó que los fertilizantes potásicos en las plantas inducen el aumento de proteínas que intervienen en el mecanismo de resistencia de la planta a las enfermedades, y Appiah et al. (2005) quienes mostraron que el movimiento de Phytophthora es más lento dentro de la planta de papa (Solanum tuberosum L.) a medida que en ella aumentan los iones de potasio, lo cual permite una menor infección en las células.

Se encontró para el tratamiento de aspersiones de $2 \mathrm{~L} \mathrm{ha}^{-1}$ de potasio foliar en estado cele una mayor incidencia de Colletotrichum sp., debido a que la germinación de esporas de hongos en la superficie de la hoja es estimulada por la concentración de aminoácidos y azúcares, la cual es alta, producto de la deficiencia de potasio, de acuerdo con Salisbury y Ross (1994).

\section{Producción de frondas}

De acuerdo con la tabla 2, se encontraron diferencias estadísticas entre los tratamientos de fertilización potásica aplicados para esta variable. La aplicación edáfica de $300 \mathrm{~kg} \mathrm{ha}^{-1}$ de potasio para frondas en estado de turión de emergencia complementada con fertilización foliar de pota- sio de 1,5 $\mathrm{L} \mathrm{ha}^{-1}$ una vez la fronda alcanzó el estado cele, presentó la mayor producción de frondas por $\mathrm{m}^{2}$, lo que concuerda con los resultados obtenidos por De Grazia et al. (2003) quienes demostraron la importancia del ajuste de los niveles de fertilización nitrogenada y potásica en el cultivo de melón (Cucumis melo L.) para promover la producción de flores y obtener altos rendimientos en forma temprana en la etapa de crecimiento. Asimismo Molina et al. (1991) al evaluar los efectos de la fertilización potásica en Gypsophila paniculata L. no encontraron diferencias significativas en el diámetro del tallo luego de dos mediciones, pero concluyeron que este factor es importante debido a que el potasio influye tanto en la calidad como en el peso de los ramos comercializados.

Aplicaciones edáficas de $400 \mathrm{~kg} \mathrm{ha}^{-1}$ de potasio para turiones de emergencia de helecho cuero, aplicaciones en forma edáfica de $200 \mathrm{~kg} \mathrm{ha}^{-1}$ de potasio en estado de turión complementada con aspersiones foliares de potasio de $1 \mathrm{~L} \mathrm{ha}^{-1}$ en estado cele, aplicaciones foliares de potasio de $2 \mathrm{~L}$ ha ${ }^{-1}$ para frondas cele y fertilizaciones en forma edáfica de $400 \mathrm{~kg} \mathrm{ha}^{-1}$ de potasio en estado cele, no presentaron diferencias estadísticamente significativas entre sí. También se encontró que la aplicación foliar de potasio de $2 \mathrm{~L}_{\text {ha }}{ }^{-1}$ mostró una baja producción de frondas por metro cuadrado, con respecto a los demás tratamientos. Estos resultados concuerdan con lo encontrado por Read et al. (2006) quienes al evaluar diferentes dosis de potasio en el cultivo de algodón (Gossypium hirsutum L.) encontraron que los diferentes niveles del nutriente afectaban la producción y la calidad de la fibra.

En la pampa argentina, algunas experiencias de fertilización con cloruro de potasio $(\mathrm{KCl})$ y sin limitaciones de otros nutrientes mostraron incrementos en la producción de materia seca en alfalfa (Medicago sativa L.) (Conti et al., 1997) e incrementos en el rendimiento en trigo (Triticum aestivum L.) (Melgar et al., 2001; Ventimiglia et al., 2003), atribuyéndose en general la respuesta a la fertilización con potasio y al efecto sobre la 
supresión en la presencia de enfermedades (Xu et al., 2000; Fixen et al., 1986).

Ensayos realizados en el norte de Buenos Aires por Ferraris y Couretot (2004), para evaluar la respuesta a KCl en una red de cultivares de trigo, mostraron que la misma fue significativa solo en un cultivar, caracterizado por su alta susceptibilidad a las enfermedades foliares. En consecuencia, en la respuesta del cultivo de trigo a la fertilización con estos nutrientes no solamente estarían involucrados el nivel de los mismos en el suelo, sino también la interacción con el genotipo utilizado y el grado de control de las enfermedades foliares.

Se ha demostrado que las aplicaciones de potasio incrementan la tasa fotosintética, el crecimiento, el rendimiento y la resistencia a la sequía en diferentes cultivos bajo condiciones de estrés hídrico. En plantas de fríjol mungo (Vigna radiata L.), maíz (Zea mays L.) y trigo (Triticum aestivum L.) crecidas bajo condiciones de estrés hídrico, las plantas nutridas con potasio mantuvieron los mayores niveles de potencial hídrico en las hojas, mayor turgencia y mayor contenido hídrico relativo así como el más bajo potencial osmótico, comparado con plantas deficientes en el elemento (Kant y Kafkafi, 2002).

\section{CONCLUSIONES}

La aplicación edáfica de cloruro de potasio $(\mathrm{KCl})$ en dosis de $300 \mathrm{~kg} \mathrm{ha}^{-1}$ en estado de turión de emergencia complementada con aspersiones foliares de potasio a razón de 1,5 L ha-1 en estado cele, mostró la mayor producción de frondas de helecho cuero con potencial exportable, y a su vez la menor incidencia de Colletotrichum sp., lo que se traduce en una mayor producción de frondas por metro cuadrado.

La aplicación foliar de potasio en dosis de $2 \mathrm{~L}$ ha-1 para frondas de helecho cuero en estado cele, mostró la mayor incidencia de Colletotrichum sp., con lo cual se debe recurrir adicionalmente a aplicaciones en forma edáfica del elemento para disminuir la incidencia del patógeno en las plantas.

La fertilización foliar de potasio a razón de $2 \mathrm{~L}$ ha-1 para frondas de helecho cuero en estado de turión de emergencia, presentó la menor producción de frondas, lo que a su vez está directamente relacionado con una baja obtención de frondas potencialmente exportables por hectárea, una vez realizada la clasificación.

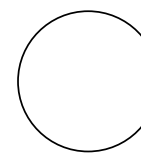

Angelova, S., M. Buchheim, D. Frowitter, A. Schierhorn y W. Roos. 2010. Overproduction of alkaloid phytoalexins in California poppy cells is associated with the co-expression of biosynthetic and stress protective enzymes. Mol. Plant 3(5), 927-939.

Agrios, N.G. 2007. Fitopatología. Editorial Limusa, México D.C.

Appiah, A., P. West, M. Osborne y A. Gow. 2005. Potassium homeostasis influences the locomotion and encystment of zoospores of plant pathogenic oomycetes. Fungal Genet. Biol. 42(3), 213-223.

Asocolflores. 2009. Informe de actividades. Asociación Colombiana de Exportadores de Flores, Bogotá.
Atehortúa, L., M. López y M. Pizano. 1997. Helecho cuero - Tree fern. Ediciones Hortitécnia, Bogotá.

Baldauf, C., N. Hanazaki y M. Reis. 2007. Caracterização etnobotânica dos sistemas de manejo de samambaia-preta (Rumohra adiantiformis (G. Forst) Ching - Dryopteridaceae) utilizados no sul do Brasil. Acta Bot. Bras. 21(4), 823-834.

Beringer, H.yF. Nothdurft. 1985. Potassium in agriculture. pp. 351-367. En: Munson, R.D. (ed.). American Society of Agronomy, Crop Science Society of America and Soil Science Society of America, Madison, WI.

Berrocal, L. 1996. Producción de follajes para la exportación. pp. 171-177. Memorias X Congreso Na- 
cional Agronómico y de Recursos Naturales y Congreso Nacional de Suelos. 8-12 julio 1996. Editorial de la Universidad Estatal a Distancia, Instituto México y Editorial Universidad Nacional de Costa Rica, San José.

Conti, M., A. De la Horra, N. Arrigo y A. Marchi. 1997. Fertilización e interacción potasio fósforo sobre el rendimiento de alfalfa en un Haplustol típico (Zona semiárida, Argentina). Ciencia Suelo $15,51-52$.

De Grazia, J., P. Tittonell, O.S. Perniola, A. Caruso y A. Chiesa. 2003. Precocidad y rendimiento en zapallito redondo de tronco (Cucurbita maxima var. zapallito (carr.) Millan) en función de la relación nitrógeno: potasio. Agricultura Técnica 63(4), 428-435.

Fageria, N. 1997. Growth and mineral nutrition of field's crops. Second edition. Marcel Dekker, New York, NY.

Ferraris, G. y L. Couretot. 2004. Estudio de la interacción entre variedades y prácticas de manejo de enfermedades. Campaña 2002/03. Informaciones Agronómicas del Cono Sur 22, 8-11.

Fitts, J.B., J.W. Fitts y A.H. Hunter. 1983. Nutrient element changes in leatherleaf ferns with different stages of growth. Proc. Flo. State Hort. Soc.96, 307-308.

Fixen, P., R. Gelderman, J. Gerwing y F. Cholick. 1986. Response of spring wheat, barley and oats to chloride in potassium chloride fertilizers. Agron. J. 78(4), 664-668.

González, C., F. Ramírezy F. Bertsh. 1998. Absorción Foliar de Fertilizantes en Helecho Hoja de Cuero ( $R$. adiantiformis (G. Forst.) Ching). Agron. Costarricense 22(2), 243-250.

Huber, D.M. 1989. Soilborne plant pathogen: management of disease with macro and microelements. APS Press, St. Paul, MN.

Jones, D. 1987. Encyclopedia of ferns. Timber Press, Oregon, OR.

Kant, S. yU. Kafkafi. 2002. Potassium and abiotic stresses in plants. pp.233-251. En: Pasricha, N.S.yS.K. Bansal (eds.). Potassium for sustainable crop production. Potash Research Institute of India, Gurgaon, India and International Potash Institute, Horgen, Suiza.

Kafkafi, U., G. Xu, P. Imas, H. Magen y J. Tarchitzky. 2001. Potassium and chloride in crops and soils: the role of potassium chloride fertilizer in crop nutrition. pp. 101-103. Research Topics No. 22. International Potash Institute, Basel, Suiza.
Marschner, H. 2002. Mineral nutrition of higher plants. Second edition. Academic Press, London.

Mäser, P., M. Gierth y J. Schroeder. 2002. Molecular mechanisms of potassium and sodium uptake in plants. Plant Soil 247, 43-54.

Melgar, R., H. Magen, M. Camozzi y J. Lavandera. 2001. Respuesta del trigo a la aplicación de cloruro de potasio en molisoles con alto contenido de potasio. Actas I Simposio "El potasio en los sistemas agrícolas argentinos". FAUBA-IPI-Fertilizar INTA, Rosario, Argentina.

Milton, S.J. 1988. Effects of harvesting on frond production of Rumohra adiantiformis (Pteridhopy: Aspidiaceae) in South Africa. J. Appl. Ecol. 25, 725-743.

Ministerio de Comercio Exterior. 2009. Importaciones colombianas por sector agro industrial. En:http:// wWw.mincomercio.gov.co/eContent/Documentos/estadisticas/volumen/imp/agroindus/volumens.xls; consulta: noviembre de 2009.

Molina, E., J. Gamboa y P. González. 1991. Fertilización potásica de Gypsophila paniculata cv. Perfecta en Paraíso, Cartago. Agron. Costarr. 15(1/2), 185-187.

Monge, M.A. 1992. Aspectos morfológicos y nutricionales del helecho hoja de cuero (Rumohra adiantiformis) en condiciones tropicales. Trabajo de grado. Escuela de Fitotecnia, Facultad de Agronomía, Universidad de Costa Rica, San José.

Pervez, H., M. Ashraf, M.I. Makhdum y T. Mahmood. 2007. Potassium nutrition of cotton (Gossypium hirsutum L.) in relation to cotton leaf curl virus disease in aridisols. Pak. J. Bot 39(2), 529-539.

Pettigrew, W.T. 2008. Potassium influences on yield and quality production for maize, wheat, soybean and cotton. Physiol. Plant. 133, 670-681.

Read, J., R. Reddy y J. Jenkins. 2006. Yield and fiber quality of Upland cotton as influenced by nitrogen and potassium nutrition. Eur. J. Agron. 24, 282-290

Reuveni, R. y M. Reuveni. 1998. Local and systemic control of powdery mildew (Leveillula taurica) on pepper plants by foliar spray of mono-potassium phosphate. Crop Prot. 17(9), 703-709.

Robertson, J.L., L. Chatfield y T. Prince. 1983. All about foliage. Flor. Rev. 172, 18-22.

Salisbury, F. y C. Ross. 1994. Fisiología vegetal. Grupo Editorial Iberoamericana. México D.C. 
Stamps, R.H. 1989. Biostimulant and high fertilizer rates do not affect leatherleaf fern frond development, yield or vase life. Proc. Fla. State Hort. Soc. 102, 274-276.

Ventimiglia, L., S. Rillo, H. Carta y P. Richmond. 2003. Evaluación de la fertilización con cloro y potasio sobre el rendimiento de trigo en 9 de Julio. Exper- imentación en campo de productores. Resultados campaña 2002/03. INTA, Centro Regional Buenos Aires Norte, Buenos Aires.

Xu, G., H. Magen, J. Trachitzky y U. Kafkafi. 2000. Advances in chloride nutrition of plants. Adv. Agron. 68, 98-150. 